\title{
Do nimble hands make for nimble lexicons? Fine motor skills predict knowledge of embodied vocabulary items
}

First Language

2014, Vol. 34(3) 244-26I (C) The Author(s) 2014

Reprints and permissions: sagepub.co.uk/journalsPermissions.nav DOI: $|0.1| 77 / 0|427237| 4535768$

fla.sagepub.com

@SAGE

\section{Sebastian P. Suggate and Heidrun Stoeger}

University of Regensburg, Germany

\begin{abstract}
Theories and research in embodied cognition postulate that cognition grounded in action enjoys a processing advantage. Extending this theory to the study of how fine motor skills (FMS) link to vocabulary development in preschool children, the authors investigated FMS and vocabulary in 76 preschoolers. Building on previous research, they hypothesized that links between FMS and vocabulary were driven by lexical items containing a greater body-object interaction (BOI). After controlling for age and part of speech (i.e., nouns vs. verbs), results indicated that FMS explained a similar amount of variance in $\mathrm{BOI}$ vocabulary as general vocabulary did. Mediation analyses indicated that the relation between FMS and general vocabulary was mediated by BOI vocabulary. To the authors' knowledge, this study provides the first evidence that FMS play a role in $\mathrm{BO}$ vocabulary development in the preschool period.
\end{abstract}

\section{Keywords}

Body-object interaction, embodied cognition, fine motor skills, vocabulary, word learning

Historically and philosophically, fine motor skills (FMS) - defined as 'small muscle movements requiring close eye-hand coordination' (Luo, Jose, Huntsinger, \& Pigott, 2007, p. 596) - have been viewed as a foundational aptitude to be fostered in

\section{Corresponding author:}

Sebastian P. Suggate, Alanus University of Arts and Social Sciences, Institute of Childhood Education,

Villestrasse 3, 53347 Alfter near Bonn, Germany.

Email: Sebastian.Suggate@alanus.edu 
early childhood and kindergarten to promote children's cognitive development. Research studies and syntheses indicate that children's FMS link to cognitive development, with FMS typically relating more strongly to spatial skills and executive functioning than to verbal skills (Cameron et al., 2012; Grissmer, Grimm, Aiyer, Murrah, \& Steele, 2010; Pagani, Fitzpatrick, Archambault, \& Janosz, 2010; Tramontana, Hooper, \& Selzer, 1988).

Given current awareness on the role of FMS in school readiness (Morrison \& Hindman, 2012), we sought to scrutinize its relation to one of the key determinants of school success, namely vocabulary development. Based on theories of embodied cognition as applied to vocabulary development (Maouene, Hidaka, \& Smith, 2008; Siakaluk, Pexman, Aguilera, Owen, \& Sears, 2006; Siakaluk et al., 2008), we investigate for the first time whether FMS in preschool children relate more strongly to general vocabulary items versus those that can be considered to be more embodied.

\section{Fine motor skills and cognitive development}

In the empirical literature, FMS are far from a unitary construct, encompassing or being interchangeable for constructs such as visual motor integration, hand-eye coordination, and (fine) manual control (e.g., Bart, Hajami, \& Bar-Haim, 2007; Dellatolas et al. 2003). Brookman and colleagues (Brookman, McDonald, McDonald, \& Bishop, 2013) categorized FMS as to whether they focused on speed, sequencing, or imitation. Based on factor analysis, Martzog and colleagues (Martzog, Chen, Stoeger, Shi, \& Ziegler, 2012) also indentified a speed component, alongside a hand-eye coordination and finger-skill component. This diversity in classification of FMS likely arises in part due to the range of disciplines in which FMS are studied (e.g., cognitive psychology, education, language development, learning disability, neuropsychology, occupational therapy, and even philosophy) and might expectedly lead to some difficulty in interpreting findings across the broad literature. To navigate this problem, we specify in the current review the FMS tasks in question. Before turning to specifically look at vocabulary development in relation to FMS, research showing the significance of the broader construct of FMS for child development is briefly outlined.

A handful of studies suggest links between an array of FMS-type constructs (including peg-moving and fine manual control) and intelligence-related cognitive skills, such as reasoning, memory, and crystallized intelligence in preschool children (Davis, Pitchford, \& Limback, 2011; Dellatolas et al., 2003; but cf. Wassenberg et al., 2005). In a longitudinal study, Grissmer et al. (2010) discovered links between FMS (i.e., copying tasks, block arrangement, parent report, figure drawing) and general school readiness, including attention skills. In one of the methodologically strongest studies published, by virtue of extensive accounting for covariates, Luo et al. (2007) explored the relations between FMS (i.e., figure copying, drawing, block arrangement) and mathematics finding a significant relation, with FMS accounting for the advantage in first grade (approx. age 6) math performance favoring Asian students. In an older literature review, Tramontana et al. (1988) identified perceptual motor skills (similar to FMS but less focused on the hands), as an important predictor of reading and math achievement. Other smaller studies confirm the relation of FMS to math and similar constructs (Bart et al., 2007; Son \& Meisels, 2006; Vacc, Vacc, \& Fogleman, 1987). However, findings 
regarding links between reading and diverse aspects of FMS are less clear, perhaps again due to the diversity in tasks used, which range from parent questionnaires to beadthreading (Cameron et al., 2012; Grissmer et al., 2010; Son \& Meisels, 2006), and in the case of reading difficulty are mixed (Viholainen et al., 2006; Viholainen et al., 2011; White et al., 2006).

In summary, FMS appear to play a role in cognitive development and school readiness, perhaps more so for spatial skills such as cognition and math than for reading. However, the strength that relations exist across a variety of different assessment and construct definitions of FMS is also a weakness, in that inconsistent results might be explained by different interpretations of FMS (e.g., Brookman et al., 2013). Furthermore, many of the studies appear to be explorative in nature, investigating links between FMS and cognitive/achievement variables, without concrete hypotheses - accordingly, particularly in older studies, sufficient control of confounding variables, such as general development and maturation, is not taken account of.

\section{Fine motor skills and vocabulary development}

Many factors influence the pace and scope of vocabulary development, such as the child's language experience at home (Boyce, Gillam, Innocenti, Cook, \& Ortiz, 2013; Nelson, Welsh, Trup, \& Greenberg, 2011; Sparks \& Reese, 2013), language-specific factors (Kambanaros, Grohmann, \& Michaelides, 2013), shared reading (Farrant \& Zubrick, 2012; McBride-Chang, 2012; Reese, 2012; Suggate, Lenhard, Neudecker, \& Schneider, 2013), and gesticulation (Hall, Rumney, Holler, \& Kidd, 2013; Rowe, Özçalişkan, \& Goldin-Meadow, 2008). Moreover, there also appear to be links between motor skill and language development, in that children with a specific language disability tend to have lesser motor and FMS (Hill, 2001; Iverson, 2010).

In terms of the relations between FMS and vocabulary development, results are mixed, although they generally indicate a positive relationship. Using large databases, robust links between FMS and receptive vocabulary have been shown to exist from preschool to second grade, that is from approximately age 4 to 7, in the US (Pagani et al., 2010). In a sample of children aged between 3 and 6 years, Dellatolas et al. (2003) found links between FMS and a mixture of receptive and expressive vocabulary. Additionally, Cameron et al. (2012) found small but significant correlations between FMS measured at age 3 and 4 and expressive vocabulary measured in kindergarten at age 6, which tended to disappear once parental and cognitive variables were controlled for. Finally, Vacc et al. (1987) found links between kindergarten FMS and a composite reading measure that included receptive vocabulary. However, Wassenberg et al. (2005) found no link between vocabulary and visuo-motor integration, a construct related to FMS.

In short, there appear to be small links between vocabulary and FMS, but research has not examined why links would exist between two seemingly disparate skills. Given that many of the above studies found links over and beyond cognitive and home factors (in particular, Pagani et al., 2010), it is unlikely that the links can be explained solely by maturational (i.e., more advanced children do generally better on both types of measure) or socioeconomic hypotheses (cf. Cameron et al., 2012). Furthermore, findings were obtained on a range of different FMS measures, thus although some measures clearly 
have a larger 'cognitive' aspect than others (e.g., drawing a figure vs. peg-shifting), this is also a strength of the work given generally convergent findings. In the next section, we consider whether the relation between FMS and vocabulary might be clarified in light of embodied theories of cognition.

\section{Embodied cognition and links between vocabulary and fine motor skills}

An old idea is that children's learning is shaped and enhanced by engaging in finely controlled motor activities, which comes to the fore in the saying 'nimble hands make for nimble minds' and in educational philosophies from the likes of Maria Montessori (Luo et al., 2007). The term embodied cognition is used to explain the long-standing idea that movement is key for learning (Barsalou, 2010) and such theories potentially provide an evidential and theoretical basis for studying links between FMS and cognitive development.

Specifically, research indicates merit in the idea that cognition grounded in action exhibits processing advantages (Barsalou, 2010). Thus, manual rotation facilitates mental rotation and vice versa (Janczyk, Pfister, Crognale, \& Kunde, 2012; Wexler, 1998; Wohlschläger, 1988). Response times to recognize objects are quicker when an associated action is first viewed (Helbig, Steinwender, Graf, \& Kiefer, 2010). Neurologically, when stimulation involves multiple sensory modalities, the association or learning is greater (Soden-Fraunhofen, von Sim, Liebich, Frank, \& Kiefer, 2007). Motor actions, cognition, and language have commonalities in the neural areas stimulated (Reynolds \& Nicolson, 2007), with a particular focus on the cerebellum (e.g., Brookman et al., 2013; Butler, James, \& James, 2011; Irannejad \& Savage, 2012), the frontal and motor cortices (Diamond, 2000; James \& Maouene, 2009). Letter processing activates areas of the brain involved during writing (James \& Gauthier, 2006; Longcamp, Anton, Roth, \& Velay, 2005).

There exists a reasonable body of evidence suggesting that verbal processing relates to action in both adults and children. Although not language in the conventional sense, learning of audio-visual combinations grounded in action leads to auditory and visual processing advantages in adults (Butler et al., 2011). Semantic language processing that is concordant with a motor action stimulates motor action (Zwaan \& Taylor, 2006). Evidence also indicates that movement and verbal processing are facilitated in children, in that manipulating objects during reading facilitates reading comprehension (Glenberg, Brown, \& Levin, 2007; Glenberg, Gutierrez, Levin, Japuntich, \& Kaschak, 2004). Two further lines of evidence are considered next, that link body parts to verb processing (Maouene et al., 2008) and show that embodied lexical items enjoy processing advantages (Siakaluk et al., 2006; Siakaluk et al., 2008).

\section{Body-object interaction - the missing link between fine motor skills and vocabulary?}

Body-object interaction (BOI) words refer to words with which a human body can more easily interact (Siakaluk et al., 2008), such as 'belt' in comparison to a low BOI word like 'clown'. Preliminary support for the idea that BOI vocabulary relates to movement and 
grounding in the body comes from Maouene et al. (2008), whereby adults consistently associated verbs with body parts and a large proportion of verbs learned in infancy were associated with the hands - the instrument of FMS. More direct support for the link between motor activity and semantic processing of BOI vocabulary has been found (Siakaluk et al., 2006; Siakaluk et al., 2008). Siakaluk et al. (2008) found faster semantic processing times for words differing in the extent to which they could be classified as having a high BOI component.

Accordingly, a tantalizing idea is that links between FMS and vocabulary - which have hitherto been elusive and mixed (Dellatolas et al., 2003; Duncan et al., 2007; Pagani et al., 2010; Wassenberg et al., 2005) - might be explained in terms of the BOI content of the vocabulary. Children who are more adept with their hands presumably have a greater array of environmental affordances open to them, which might facilitate BOI vocabulary development. For example, children who have greater FMS, might engage in more play with crafts and acquire words and concepts such as delicate, seam, and envelope; or through play with balls (with an adult) encounter words such as juggling, balance, and poise. Given links between FMS and cognitive development (e.g., Grissmer et al., 2010) and also links between the hands and vocabulary (i.e., Maouene et al., 2008), there appears to be tentative reason to suppose links between FMS and vocabulary exist, albeit predominantly for BOI vocabulary items.

However, to investigate whether FMS are important in children's vocabulary development, research needs to be extended in several directions. To build on the work of Siakaluk et al. (2006; Siakaluk et al., 2008), both children's general and BOI vocabulary needs to be investigated, whereas previous work has only investigated general vocabulary (Duncan et al., 2007; Pagani et al., 2010). Additionally, the strength of the associations between BOI vocabulary and FMS needs to be compared with those between FMS and general vocabulary to see whether BOI plays a role. Conceivably, the mixed findings on the links between FMS and general vocabulary might be clarified by considering words' BOI ratings. Furthermore, given that the hand is the instrument of FMS, it is conceivable that words relating more specifically to interactions with the hand show greater links to FMS - however, no research has to date examined this link.

\section{The current study}

To our knowledge, no study - particularly with preschool children - has tested the idea that FMS relate to BOI vocabulary, with this perhaps explaining mixed findings on the link between FMS and general vocabulary, therefore we conducted such a study. Preschool children completed tests of general vocabulary, BOI vocabulary, and FMS. Crucially, we took words from the German adaptation (Lenhard, Segerer, Lenhard, \& Suggate, 2013) of the Peabody Picture Vocabulary Test-IV (Dunn \& Dunn, 2007) because these lexical items are expectedly mastered to differing degrees in preschool children yet are all represented by pictures, thus ruling out that imageability confounds relations with BOI (see Siakaluk et al., 2008). Furthermore, we divided the PPVT-IV test into two parts, one part of which was used to estimate BOI vocabulary and the other general vocabulary, thus controlling for general vocabulary and testing procedure. In addition to controlling for imageability and testing procedure, we include controls for part of speech 
(i.e., nouns, verbs) and maturation, the latter because links between vocabulary and FMS might be explainable by age. Moreover, we used new measures of FMS designed to be independent of early academic skills such as writing, but which have shown links to reasoning (Martzog et al., 2012).

Our first aim was to add to the small body of research investigating links between FMS and vocabulary development in preschool children (aged under 6) and, second, to examine these links in the light of whether vocabulary items are embodied. Specifically, we hypothesized that the links between FMS and vocabulary would be greater for words that have a high BOI component. Third, we tested the additional hypothesis that words directly manipulable in the hand would show greater relations with FMS than more generally BOI words, because of being more tightly coupled to FMS. Finally, in light of previous mixed findings on links between vocabulary and FMS, we test the hypothesis that BOI vocabulary mediates the relations between FMS and general vocabulary.

\section{Method}

\section{Participants}

The participants in this study were 76 (from an original 82) children aged on average 4;9 $(S D=10.97$ months) attending kindergartens (the closest US equivalent is preschool) in a small city with a population of approximately 130,000 people in southern Germany. The percentage of parents born in Germany was $88.80 \%$ on average, for children this was $93.40 \%$ and $18.40 \%$ spoke a second language other than German at home. Exactly $50.00 \%$ were girls and $10.60 \%$ were identified as being left handed. In terms of educational attainment, $71.80 \%$ of mothers and $76.90 \%$ of fathers had completed a secondary school qualification and $52.60 \%$ of mothers and $48.00 \%$ of fathers had obtained a university degree. Thus the current sample, compared to the German average of $26.60 \%$, could be considered well educated (Organisation for Economic Cooperation and Development [OECD], 2013).

\section{Measures}

Demographics. Upon giving parental consent for their children's participation, parents were asked to complete a questionnaire containing information of theirs and their child's country of birth, languages spoken at home, and educational achievement at secondary and tertiary levels.

Fine motor skills. The FMS tests were taken from a battery designed to provide an estimate of children's FMS in preschool. Here we selected the three tasks that closely adhered to our definition of FMS as being meaningful and directed small muscle movements of the hand and excluded tapping and visuo-motor integration tasks (Luo et al., 2007). A further reason for selecting these tasks was that they constitute a unitary factor that exhibited, in comparison to tapping (see also Brookman et al., 2013) and broader manual control measures, stronger relations with WISC (Wechsler Intelligence Scale for Children) reasoning tasks in preschool children (Martzog et al., 2012). Children 
completed tasks with their dominant hand and were asked to hold a small block in their non-dominant hand to discourage use thereof. Cronbach's alpha coefficients for the hand skill tasks have been reported at around 87 (Martzog et al., 2012).

Peg-board task. The first of the FMS measures was a peg-board task in which children were required to insert pegs as quickly as they could into a peg-board to form a row (peg insertion). There were a total of 24 pegs. In the second part of the task, children were required to take the pegs out of their holes and insert them into a new row (peg-shifting). Two scores were recorded reflecting the time taken to insert or shift all pegs and the number of pegs inserted or shifted within 35 seconds. The experimenter demonstrated the task by shifting three pegs and then the children first practiced moving five pegs. The maximum score possible was 24 in each phase.

Bead-threading. In a bead-threading task children were required to take beads, one at a time, out of a small container and place these on a metal rod protruding slightly through a $10 \mathrm{~cm}$ hole. The rod held exactly 20 beads and again two scores were taken; the number of beads threaded in 60 seconds and the time taken to thread all 20. If a child dropped a bead on the floor, he or she was instructed to continue without collecting the dropped bead. The experimenter demonstrated on three items and then the child practiced three items before beginning the trial.

Block-turning. The third hand skill task was a block-turning task in which children had to flip 16 small cylinders inserted into slots in a wooden board. The 16 cylinders comprised the 'coat' of a clown drawn on the board and the children were asked to make the coat red and then back to blue by flipping each cylinder. Thus six scores were provided; number of cylinders turned to 'red' and then back to 'blue' in 28 and then 40 seconds; and then the duration to turn all cylinders 'red' and then back to 'blue'. Here again the experimenter demonstrated three items and then the child practiced three items before beginning the trial.

General vocabulary. For this study we used a German translation of the Peabody Picture Vocabulary Test-IV (PPVT-IV) (Dunn \& Dunn, 2007). In this widely used test, experimenters read aloud a word and children indicate which of a possible four pictures best matches that word. The test begins with more elementary items and becomes increasingly difficult until either the end of the test or a ceiling criterion is reached. Previous work with this translation indicates significant correlations in German with vocabulary learning from listening to stories $(r=.40)$, reading comprehension $(r=.46)$ (Suggate et al., 2013), and early reading skills (Suggate, Reese, Lenhard, \& Schneider, 2014). The test has a maximum possible score of 228 .

BOI and FMS-manipulable words. To create an estimate of children's BOI vocabulary, we built a score based on items 37 to 72 of the PPVT-IV test. We selected these items because these were items completed by 78 of the 82 children in the study. Of the 36 items, 28 were nouns, six were verbs, and two were adjectives. While viewing the corresponding pictures in the test, three researchers (the study authors plus an independent 
corroborator) with expertise in FMS research independently rated each of the 36 items on a five-point Likert scale ( $1=$ not at all to $5=$ very much so $)$ according to the questions: 'To what extent can a human body physically interact with the word's referent?' and 'Is the word's referent physically manipulable with your hands?' The first question, derived from Siakaluk et al. (2008), was used to form the BOI-vocabulary scale and the second question was used to form the FMS-manipulable scale. Inter-rater agreement was estimated to be good for the BOI-vocabulary scale, Cronbach's alpha $=.78, \mathrm{ICC}=.78$, and for the FMS-manipulable scale, Cronbach's alpha $=.84, \mathrm{ICC}=.83$. As mentioned, the vocabulary items were taken from a picture vocabulary test to rule out the confounding factor of imageability (Siakaluk et al., 2008). The average of all three raters was taken as the BOI and FMS-manipulable rating for each item in the vocabulary test. Children's BOI and FMS-manipulable vocabulary scores were then calculated by summing up the BOI ratings for each of the correctly identified words. For example, the word 'feather' received a mean BOI rating of 5 and the word 'roof' 1.67, such that a child correctly identifying only these two words would receive a BOI rating of 6.67 . The words and the researchers' ratings of BOI are presented in the Appendix 1. Additionally, separate estimates were provided for the nouns and verbs in the test.

General vocabulary estimate. A statistically independent estimate of general vocabulary was calculated for analyses because the total PPVT-IV score could not be used as items 37 to 72 fed into the BOI vocabulary score. Therefore, children's general vocabulary scores between items 73 and 144 were summed to provide a general vocabulary estimate, using as much of the data as possible to obtain the best estimate (hence 72 items instead of 36 for the BOI vocabulary). It was necessary to restrict the item range to item 144 because in four cases, due to experimental error or child refusal to continue taking the PPVT-IV test, the ceiling rule was not properly adhered to. From available data, this general estimate correlated highly with the entire PPVT-IV scale, $r(77)=.94, p<.001$, and also with the score for items 37 to $72, r(81)=.64, p<.001$, supporting the use of the reduced estimate as a proxy for the entire scale.

\section{Procedure}

Letters inviting children to participate in the study were sent to the parents of children attending urban kindergartens willing to participate in the study. Children were tested one at a time on site in the kindergartens, usually for around 45 minutes. To determine the dominant hand for the FMS tasks and build rapport, a handedness test was first conducted by asking children to show how they brush their teeth, ring a bell, cut a piece of paper with scissors, and draw a tree. All tests were conducted by trained undergraduate education or psychology students according to the instructions in the test manuals. To ensure accurate administration, each of the researchers was supervised for the first several trials, until administration procedures were exactly adhered to.

\section{Results}

Four children's data were discarded from the analysis because they did not reach item 72 , i.e., the basal item for calculation of the BOI vocabulary score. Descriptive statistics 
Table I. Descriptive statistics for entire preschool sample.

\begin{tabular}{llrrrr}
\hline & M & \multicolumn{1}{l}{ SD } & \multicolumn{1}{c}{$n$} & \multicolumn{1}{c}{ Min. } & \multicolumn{1}{c}{ Max. } \\
\hline Age & 57.30 & 10.80 & 74 & 39.00 & 76.00 \\
General vocabulary (completed test) & 98.82 & 27.55 & 72 & 48.00 & 153.00 \\
Vocabulary score (items 37-72) & 27.20 & 15.37 & 76 & 5.00 & 34.00 \\
Vocabulary estimate (items 73-144) & 31.14 & 15.96 & 76 & 0.00 & 52.00 \\
BOI vocabulary total & 83.62 & 13.80 & 76 & 18.00 & 102.68 \\
BOI vocabulary nouns & 63.39 & 9.61 & 76 & 15.00 & 76.34 \\
BOI vocabulary verbs & 18.62 & 4.35 & 76 & 3.00 & 24.00 \\
FMS-manipulable vocabulary total & 81.32 & 13.78 & 76 & 17.67 & 100.66 \\
FMS-manipulable vocabulary nouns & 63.54 & 10.17 & 76 & 14.67 & 78.33 \\
FMS-manipulable vocabulary verbs & 18.62 & 4.35 & 76 & 3.00 & 24.00 \\
Fine motor skills & & & & & \\
Peg insertion & 11.85 & 2.68 & 75 & 6.00 & 18.00 \\
Peg-shifting & 18.17 & 3.80 & 75 & 10.00 & 24.00 \\
Bead-threading & 15.17 & 3.71 & 72 & 6.00 & 20.00 \\
Block-turning I & 12.19 & 3.06 & 74 & 3.00 & 16.00 \\
Block-turning 2 & 12.59 & 3.31 & 73 & 2.00 & 16.00 \\
\hline
\end{tabular}

were calculated for the measured variables and these are presented in Table 1. Inspection of distributions, kurtosis, and skewness statistics revealed that the BOI score was positively skewed so this was square transformed, which reduced the skew and kurtosis (from -1.58 to -.64 and from 4.56 to .35 , respectively). Varimax factor analyses with mean replacement were used to create a general estimate of FMS given the small proportion of missing data for some subtests (see Table 1). A single factor solution appeared optimal, explaining 59.29\% of the variance in the FMS measures. This variable was used in all subsequent analyses. After inspecting skew and kurtosis statistics, BOI and manipulable vocabulary for nouns and verbs and the total scale were square transformed to reduce kurtosis into a range representing a non-violation of statistical normality (kurtosis $<2.00)$.

As can be seen in Table 1, participants were slightly younger than 5 years on average. Importantly, the means for the items were placed well outside of one standard deviation of the minimum and maximum scores, suggesting further that floor and ceiling effects were avoided. Reflecting the increasing difficulty of the general vocabulary test, children scored a similar number of points for the 72-item general vocabulary test in comparison to the 36-item BOI vocabulary items. In addition to the descriptives in Table 1, gender differences were explored. Girls had significantly greater overall FMS scores, $t(72)=$ $4.80, p<.01$, despite not being significantly older, $t(71)=1.69, p=.10$, not having significantly better general vocabulary, $t(72)=1.07, p=.29$, and not having better BOI vocabulary, $t(72)=1.63, p=.11$.

Next correlation coefficients between FMS, general vocabulary, BOI and FMSmanipulable vocabulary (both nouns and verbs), and the general vocabulary estimate (containing items between 72 and 144) were calculated. FMS correlated highly with age, $r=.81, p<.001$, general vocabulary, $r=.66, p<.001$, BOI vocabulary, $r=.70, p<.001$, 
and manipulable vocabulary, $r=.70, p<.001$. Correlations (Table 2) controlling for age, showed that links still existed between FMS and general, manipulable, and BOI vocabulary.

In Table 3, regression analyses are reported to test the role that FMS play in BOI vocabulary and FMS-manipulable vocabulary, while accounting for general vocabulary and age. The reason for this analysis was to test whether FMS related uniquely to FMS vocabulary items while accounting for general vocabulary. The analyses in Table 3 indicate almost identical coefficients, regardless of whether the dependent variable was BOI or FMS-manipulable vocabulary. Identical regression analyses conducted for nouns and verbs separately found highly similar relations, regardless of whether the word was a noun or a verb. Even after controlling for age and general vocabulary, independent variance in embodied vocabulary was explained by FMS.

Finally, we conducted a mediational analysis to test whether the link between vocabulary and FMS was mediated by BOI vocabulary. In conducting this test, we again include age as a covariate to account for maturation. The resulting mediation analysis depicted in Figure 1 suggested a statistically significant mediational effect of BOI vocabulary on the relation between FMS and general vocabulary, as confirmed by a Sobel test, $Z=3.02, S E$ $=1.43, p<.01$. A further analysis confirmed a similar mediation effect for BOImanipulable vocabulary, $Z=2.89, S E=1.37, p<.01$.

\section{Discussion}

We tested the idea and previous findings that FMS play a role in vocabulary development in early childhood. In doing so, we extended previous work by incorporating insights from theories and research in embodied cognition and looking specifically at the role of BOI vocabulary. We hypothesized that weak and inconsistent associations (Brookman et al., 2013; Dellatolas et al., 2003; Duncan et al., 2007; Pagani et al., 2010; Wassenberg et al., 2005) between FMS and vocabulary could be reconsidered in light of whether lexical entries reflected a BOI component. In terms of general vocabulary, our study added to the research by showing that FMS and general vocabulary do correlate somewhat ( $r=$ $.27)$, even after controlling for age.

Crucially, we found evidence that the extent to which a human body can interact with a word's referent determines its relation to FMS. After controlling for age, general vocabulary, and part of speech in the regression analyses, children's performance at recognizing words with an embodied component was related to their performance on FMS tasks. Both verbs and nouns appeared to link to FMS, which is consistent with wordembodiment links found in previous studies (Maouene et al., 2008; Siakaluk et al., 2008).

Furthermore, our mediational analysis suggested that the link between FMS and general vocabulary is almost entirely explained by children's BOI and manipulable vocabulary. This suggests that advantages that children have for vocabulary development arising from FMS are largely confined to words that relate to body-object interactions, to words which entail a motor activity. Therewith, we tentatively postulate that previous mixed findings linking vocabulary to FMS (Cameron et al., 2012; Pagani et al., 2010; Wassenberg et al., 2005) might be clarified by taking explicit account of the words' BOI characteristics. Accordingly, we interpret these findings as being consistent with 


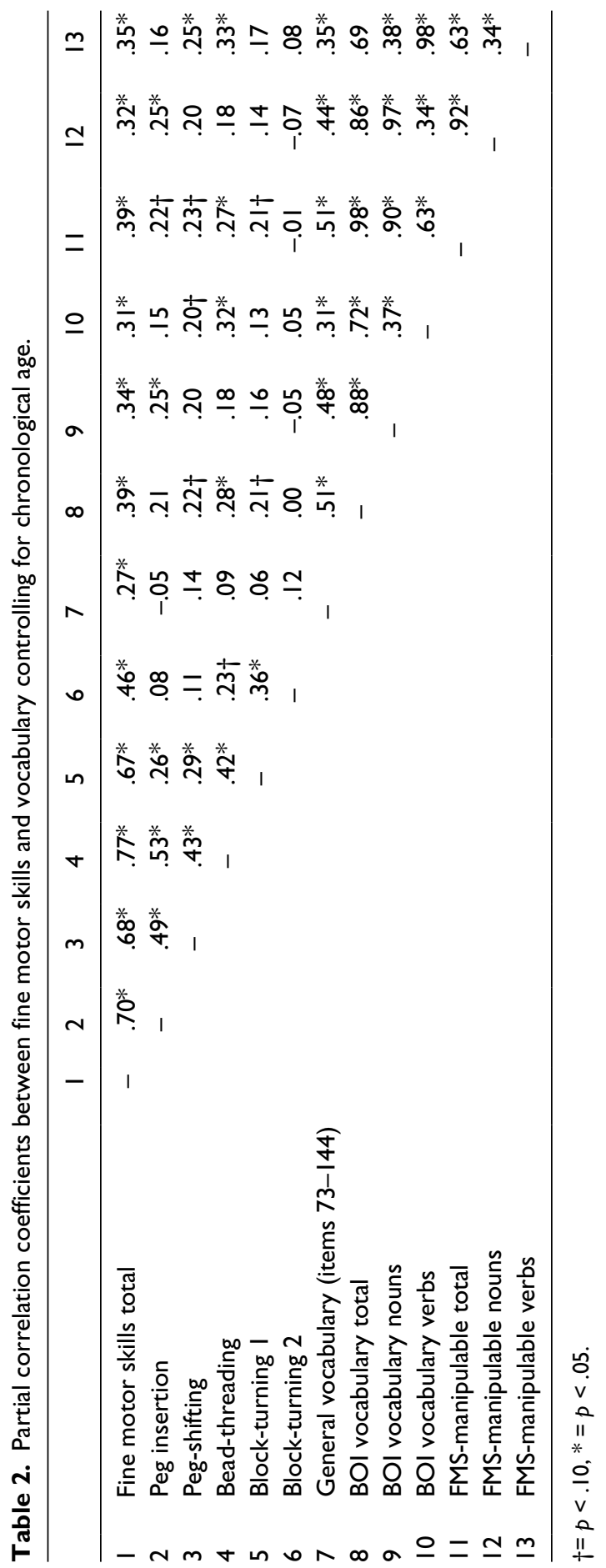


Table 3. Regression analyses predicting $\mathrm{BOI}$ vocabulary from FMS, age, and vocabulary.

\begin{tabular}{|c|c|c|c|c|c|c|c|c|c|}
\hline \multirow[t]{2}{*}{ Step } & \multirow[t]{2}{*}{ Variable } & \multicolumn{4}{|c|}{ FMS-manipulable vocabulary } & \multicolumn{4}{|c|}{ BOI vocabulary } \\
\hline & & $B$ & SE B & $\beta$ & $\Delta R^{2}$ & B & SE B & $\beta$ & $\Delta R^{2}$ \\
\hline \multirow[t]{2}{*}{ I } & Intercept & 6972.43 & 139.69 & & $.58 * * *$ & 7356.28 & 141.83 & & $.58 * * *$ \\
\hline & Fine motor skills & 1431.27 & 142.78 & $.76 * * *$ & & $144 \mid .97$ & 144.97 & $.76 * * *$ & \\
\hline \multirow[t]{3}{*}{2} & Intercept & 5216.29 & 344.55 & & $.12^{* *}$ & 5590.13 & 351.20 & & $.12^{* *}$ \\
\hline & Fine motor skills & 825.55 & 164.54 & $.44 * * *$ & & 832.80 & |67.7| & $.44^{* * *}$ & \\
\hline & Vocabulary estimate & 55.91 & 10.30 & $.48 * * *$ & & 56.23 & 10.50 & $.47^{* *}$ & \\
\hline \multirow[t]{4}{*}{3} & Intercept & 2953.88 & 1047.61 & & $.02 *$ & 3356.73 & 1070.30 & & $.02 *$ \\
\hline & Fine motor skills & 527.58 & 206.53 & $.28 *$ & & 538.65 & 211.00 & $.28 *$ & \\
\hline & Vocabulary estimate & 47.77 & 10.63 & $.4 I^{* * *}$ & & 48.19 & 10.86 & $.4 I^{* * *}$ & \\
\hline & Age & 43.72 & 19.18 & $.26^{*}$ & & 43.15 & 19.60 & $.25^{*}$ & \\
\hline
\end{tabular}

$*=p<.05$.

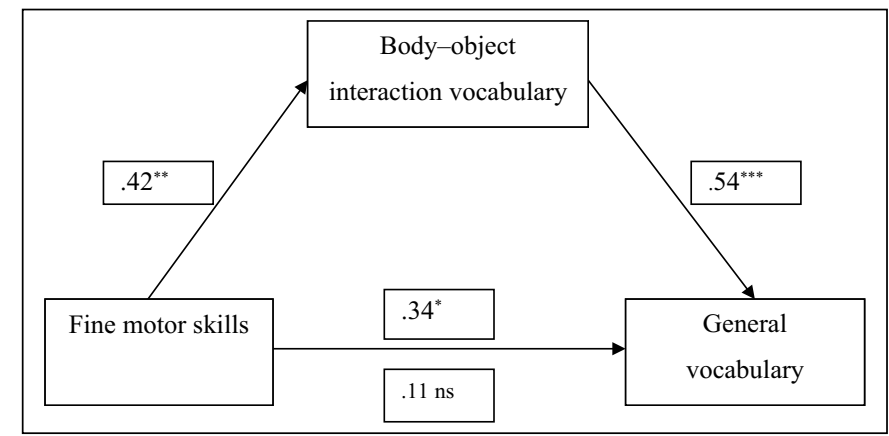

Figure I. Body-object interaction vocabulary mediates the relation between general vocabulary and fine motor skills while controlling for age.

$*=p<.05, * *=p<.01, * * *=p<.00 \mathrm{I}, \mathrm{c}=.34^{*}$, and $\mathrm{c}^{\prime}=.1 \mathrm{I}$ ns.

embodied cognition theories and research (Barsalou, 2008, 2010; Glenberg et al., 2007; Glenberg \& Gallese, 2011; Glenberg, Goldberg, \& Zhu, 2011; Glenberg et al., 2004; Helbig et al., 2010).

Key differences between the current study and previous work looking at BOI exist. First, this was the first study looking at BOI in preschool children and linking it to FMS. Second, we took items from a renowned vocabulary test for preschool children (i.e., PPVT-IV) and split the test in two to create controls for general vocabulary and test construction. Specifically, frequency of the words' appearance in language, imageability, and some feature of test administration or format would be automatically partialed out by virtue of covarying general vocabulary with BOI vocabulary. Moreover, the categories of abstractness (e.g., get, bring; Maouene, Sethuraman, Laakso, \& Maouene, 2011) were also indirectly partialed out, in that none of the words in the BOI vocabulary test could be considered abstract in this sense. Therefore, the splitting of the test, assigning ratings 
to each word, and the correlational design made it less likely that some unaccounted methodological factor explains the links with FMS.

Importantly, our findings are not consistent with solely maturational accounts for the link between FMS and vocabulary development. Given the high correlation observed between age and general vocabulary $(r=.69)$ and age and FMS $(r=.81)$ - the latter of which was greater than that between FMS and BOI vocabulary, $r=.70-$ there is evidence consistent with a large maturational component that drives both the development of FMS and vocabulary. Conversely, because experience and maturation are both correlated, it could be that chronological age was operating as a proxy for experiences leading to links to BOI vocabulary acquisition. By virtue of demonstrating relations between BOI and manipulable vocabulary and FMS over and beyond age and general vocabulary in the regression analyses, we reduce the possibility that maturation determined links with FMS. However, our strongest evidence that maturation is not the sole factor driving FMS and vocabulary development is the differential finding between FMS and BOI words vs. general vocabulary, even after controlling for age in the regression equations. If maturation were the sole driving factor then links between FMS and BOI vocabulary should be the same as those between FMS and general vocabulary.

Although our findings clearly indicate differential relations between FMS and BOI vs. general vocabulary, it is premature to conclude that this constitutes direct support for embodied cognition theories. Specifically, similar to previous studies (Helbig et al., 2010; Maouene et al., 2008; Siakaluk et al., 2008; Soden-Fraunhofen et al., 2007), we showed links in learners that had already embodied the BOI vocabulary and thus could not test how these arose. For example, our study cannot logically favor the interpretation that FMS lead to improved BOI vocabulary over the explanation that children with greater BOI vocabulary seek out experiences relating to FMS, due to their greater knowledge about FMS concepts. Our study was a necessary first step to pave the way for a cross-paneled longitudinal or experimental design, which would provide stronger support for embodied cognition theories.

An important aspect of future work also needs to investigate factors affecting the embodiment of cognition. Presumably, children with greater FMS are able to both engage in a richer variety of actions and thereby experience a richer array of cognitions, which are in turn more deeply processed. According to this idea, FMS would then act as both an enabling factor and a facilitative factor in vocabulary development. To test this hypothesis more closely, research needs to take account of the kinds of activities children engage in and whether greater BOI or manipulable vocabulary skills are thus acquired. This would be akin to testing for a kind of mediated moderator effect, whereby children with greater FMS (i.e., moderation) can engage in activities that then mediate cognitive development. Furthermore, future research ought to investigate whether nouns or verbs are differentially related to FMS in this age of children, by using a larger language sample. The current findings suggest that a word's embodiment determines its link with FMS more than its part of speech. However, given that we had only six BOI verbs in this study, more research is needed.

Although the findings are consistent with embodied cognition theories, it is also possible that other factors influencing language acquisition might have led to the current results. Iverson (2010) argues that the emergence of motor skills, and perhaps therewith 
FMS, allows children to more actively explore and interact with their environments, thus facilitating both vocabulary development and links between vocabulary and FMS. Likewise, given the role of gesture (Rowe et al., 2008) and imitation in vocabulary development (Hall et al., 2013), these also might help link vocabulary with motor development, leading to 'body region correlates' of word learning (Maouene et al., 2011, p. 449), similar to the kind of BOI associations observed here.

Methodologically, we interpret our findings cautiously for several reasons. First, we did not assign the words to the BOI ratings in a randomized fashion, thus it is possible that some feature of the words other than their manipulability or BOI caused their relation with FMS. Likewise, some feature of child development such as general health might cause both FMS and interaction with objects leading to greater BOI vocabularies. Accordingly, future research could experimentally assign words to embodiment, perhaps by employing a word learning paradigm with nonsense words, although this would result in a loss of validity. Alternatively, a motor interference task could be used on half of the words to disrupt the BOI advantage.

In summary, the findings from this study appear to provide the first evidence in preschool age children that potentially enhances our understanding of why FMS have been shown to link to vocabulary development. The findings provide preliminary support for the idea that language development does not occur in isolation from motor development, which likely has the important implication that small children should be given ample opportunity to engage in both activities. Therewith, future research could include information on the kinds of activities that children perform and link this to subsequent vocabulary and, more generally, cognitive development, to test whether nimble hands do indeed make for nimble minds.

\section{Acknowledgements}

We would like to thank Elisabeth Werner, Veronika Gühmann, Agnetha Henne, Juliane Biedermann, and Carolin Boehmer for their help collecting data.

\section{Funding}

This research received no specific grant from any funding agency in the public, commercial, or not-for-profit sectors.

\section{References}

Barsalou, L. W. (2008). Grounded cognition. Annual Review of Psychology, 59, 617-645. doi:10.1146/annurev.psych.59.103006.093639

Barsalou, L. W. (2010). Grounded cognition: Past, present, and future. Topics in Cognitive Science, 2, 716-724. doi:10.1111/j.1756-8765.2010.01115.x

Bart, O., Hajami, D., \& Bar-Haim, Y. (2007). Predicting school adjustment from motor abilities in kindergarten. Infant and Child Development, 16, 597-615. doi:10.1002/icd.514

Boyce, L. K., Gillam, S. L., Innocenti, M. S., Cook, G. A., \& Ortiz, E. (2013). An examination of language input and vocabulary development of young Latino dual language learners living in poverty. First Language, 33, 572-593. doi:10.1177/0142723713503145

Brookman, A., McDonald, S., McDonald, D., \& Bishop, D. V. (2013). Fine motor deficits in reading disability and language impairment: Same or different? PeerJ, 1(3), e217. doi:10.7717/ peerj. 217 
Butler, A. J., James, T. W., \& James, K. H. (2011). Enhanced multisensory integration and motor reactivation after active motor learning of audiovisual associations. Journal of Cognitive Neuroscience, 23, 3515-3528.

Cameron, C. E., Brock, L. L., Murrah, W. M., Bell, L. H., Worzalla, S. L., Grissmer, D., \& Morrison, F. J. (2012). Fine motor skills and executive function both contribute to kindergarten achievement. Child Development, 83, 1229-1244. doi:10.1111/j.1467-8624.2012.01768.x

Davis, E. E., Pitchford, N. J., \& Limback, E. (2011). The interrelation between cognitive and motor development in typically developing children aged 4-11 years is underpinned by visual processing and fine manual control. British Journal of Psychology, 102, 569-584. doi:10.1111/j.2044-8295.2011.02018.x

Dellatolas, G., De Agostini, M., Curt, F., Kremin, H., Letierce, A., Maccario, J., \& Lellouch, J. (2003). Manual skill, hand skill asymmetry, and cognitive performances in young children. Laterality: Asymmetries of Body, Brain, and Cognition, 8, 317-338. doi:10.1080/1357650

Diamond, A. (2000). Close interrelation of motor development and cognitive development and of the cerebellum and prefrontal cortex. Child Development, 71, 44-56.

Duncan, G. J., Dowsett, C. J., Claessens, A., Magnuson, K., Huston, A. C., Klebanov, P., . .Japel, C. (2007). School readiness and later achievement. Developmental Psychology, 43, 1428-1446. doi:10.1037/0012-1649.43.6.1428

Dunn, L., \& Dunn, D. (2007). PPVT-4, Peabody Picture Vocabulary Test Manual (4th ed.). Minneapolis, MN: Pearson Assessments.

Farrant, B. M., \& Zubrick, S. R. (2012). Early vocabulary development: The importance of joint attention and parent-child book reading. First Language, 32, 343-364. doi: $10.1177 / 0142723711422626$

Glenberg, A. M., Brown, M., \& Levin, J. (2007). Enhancing comprehension in small reading groups using a manipulation strategy. Contemporary Educational Psychology, 32, 389-399. doi:10.1016/j.cedpsych.2006.03.001

Glenberg, A. M., \& Gallese, V. (2011). Action-based language: A theory of language acquisition, comprehension, and production. Cortex. Advance online publication. doi:10.1016/j. cortex.2011.04.010

Glenberg, A. M., Goldberg, A. B., \& Zhu, X. (2011). Improving early reading comprehension using embodied CAI. Instructional Science, 39, 27-39. doi:10.1007/s11251-009-9096-7

Glenberg, A. M., Gutierrez, T., Levin, J. R., Japuntich, S., \& Kaschak, M. P. (2004). Activity and imagined activity can enhance young children's reading comprehension. Journal of Educational Psychology, 96, 424-436. doi:10.1037/0022-0663.96.3.424

Grissmer, D., Grimm, K. J., Aiyer, S. M., Murrah, W. M., \& Steele, J. S. (2010). Fine motor skills and early comprehension of the world: Two new school readiness indicators. Developmental Psychology, 46, 1008-1017.

Hall, S., Rumney, L., Holler, J., \& Kidd, E. (2013). Associations among play, gesture and early spoken language acquisition. First Language, 33, 294-312. doi:10.1177/0142723713487618

Helbig, H. B., Steinwender, J., Graf, M., \& Kiefer, M. (2010). Action observation can prime visual object recognition. Experimental Brain Research, 200, 251-258. doi:10.1007/s00221-009-1953-8

Hill, E. L. (2001). Non-specific nature of specific language impairment: A review of the literature with regard to concomitant motor impairments. International Journal of Language \& Communication Disorders, 36, 149-171. doi:10.1080/13682820010019874

Irannejad, S., \& Savage, R. (2012). Is a cerebellar deficit the underlying cause of reading disabilities? Annals of Dyslexia, 62, 22-52. doi:10.1007/s11881-011-0060-2

Iverson, J. M. (2010). Developing language in a developing body: The relationship between motor development and language development. Journal of Child Language, 37, 229-261. doi:10.1017/S0305000909990432 
James, K. H., \& Gauthier, I. (2006). Letter processing automatically recruits a sensory-motor brain network. Neuropsychologia, 44, 2937-2949. doi:10.1016/j.neuropsychologia.2006.06.026

James, K. H., \& Maouene, J. (2009). Auditory verb perception recruits motor systems in the developing brain: An fMRI investigation. Developmental Science, 12, F26-F34. doi:10.1111/ j.1467-7687.2009.00919.x

Janczyk, M., Pfister, R., Crognale, M. A., \& Kunde, W. (2012). Effective rotations: Action effects determine the interplay of mental and manual rotations. Journal of Experimental Psychology: General, 141, 489-501. doi:10.1037/a0026997

Kambanaros, M., Grohmann, K. K., \& Michaelides, M. (2013). Lexical retrieval for nouns and verbs in typically developing bilectal children. First Language, 33, 182-199. doi: $10.1177 / 0142723713479435$

Lenhard, A., Segerer, R., Lenhard, W., \& Suggate, S. (2013, 23-25 September). Deutsche Adaption des Peabody Picture Vocabulary Test IV [German adaptation of the Peabody Picture Vocabulary Test IV]. 14. Fachgruppentagung Pädagogische Psychologie, Hildesheim, Germany.

Longcamp, M., Anton, J.-L., Roth, M., \& Velay, J.-L. (2005). Premotor activations in response to visually presented single letters depend on the hand used to write: A study on left-handers. Neuropsychologia, 43, 1801-1809. doi:10.1016/j.neuropsychologia.2005.01.020

Luo, Z., Jose, P. E., Huntsinger, C. S., \& Pigott, T. D. (2007). Fine motor skills and mathematics achievement in East Asian American and European American kindergartners and first graders. British Journal of Developmental Psychology, 25, 595-614. doi:10.1348/0261510 07X185329

Maouene, J., Hidaka, S., \& Smith, L. (2008). Body parts and early-learned verbs. Cognitive Science: A Multidisciplinary Journal, 32, 1200-1216. doi:10.1080/03640210802019997

Maouene, J., Sethuraman, N., Laakso, A., \& Maouene, M. (2011). The body region correlates of concrete and abstract verbs in early child language. Cognition, Brain, Behavior: An Interdisciplinary Journal, 15, 449-484.

Martzog, P., Chen, W., Stoeger, H., Shi, J., \& Ziegler, A. (2012). Specifying relations between fine motor skills and cognitive abilities: A cross-cultural study. In H. Stoeger, A. Aljughaiman, \& B. Harder (Eds.), Talent development and excellence (pp. 135-154). Münster, Germany: LIT.

McBride-Chang, C. (2012). Shared book reading: There is no downside for parents. In S. P. Suggate \& E. Reese (Eds.), Contemporary debates in child development and education (pp. 51-58). London, UK: Routledge, Taylor \& Francis.

Morrison, F. J., \& Hindman, A. H. (2012). Promoting school readiness: An integrative framework. In S. P. Suggate \& E. Reese (Eds.), Contemporary debates in child development and education (pp. 133-142). London, UK: Routledge, Taylor \& Francis.

Nelson, K. E., Welsh, J. A., Trup, E. M. V., \& Greenberg, M. T. (2011). Language delays of impoverished preschool children in relation to early academic and emotion recognition skills. First Language, 31, 164-194. doi:10.1177/0142723710391887

Organisation for Economic Cooperation and Development. (2013). Retrieved from http://www. oecd.org/

Pagani, L. S., Fitzpatrick, C., Archambault, I., \& Janosz, M. (2010). School readiness and later achievement: A French Canadian replication and extension. Developmental Psychology, 46, 984-994.

Reese, E. (2012). The tyranny of shared book-reading. In S. P. Suggate \& E. Reese (Eds.), Contemporary debates in child development and education (pp. 59-68). London, UK: Routledge, Taylor \& Francis.

Reynolds, D., \& Nicolson, R. I. (2007). Follow-up of an exercise-based treatment for children with reading difficulties. Dyslexia, 13, 78-96. doi:10.1002/dys.331 
Rowe, M. L., Özçalişkan, S., \& Goldin-Meadow, S. (2008). Learning words by hand: Gesture's role in predicting vocabulary development. First Language, 28, 182-199. doi: $10.1177 / 0142723707088310$

Siakaluk, P. D., Pexman, P. M., Aguilera, L., Owen, W. J., \& Sears, C. R. (2006). Evidence for the activation of sensorimotor information during visual word recognition: The body-object interaction effect. Cognition, 106, 433-443. doi:10.1016/j.cognition.2006.12.011

Siakaluk, P. D., Pexman, P. M., Sears, C., Wilson, K., Locheed, K., \& Owen, W. (2008). The benefits of sensorimotor knowledge: Body-object interaction facilitates semantic processing. Cognitive Science: A Multidisciplinary Journal, 32, 591-605. doi:10.1080/03640210802035399

Soden-Fraunhofen, R., von Sim, E., Liebich, S., Frank, K., \& Kiefer, M. (2007). Die Rolle der motorischen Interaktion beim Erwerb begrifflichen Wissens: Eine Trainingsstudie mit künstlichen Objekten [The role of motor interactions during the acquisition of conceptual knowledge: A training study with novel objects]. Zeitschrift für Pädagogische Psychologie, 22, 47-58. doi:10.1024/1010-0652.22.1.47

Son, S.-H., \& Meisels, S. J. (2006). The relationship of young children's motor skills to later school achievement. Merrill-Palmer Quarterly, 52, 755-778. doi:10.1353/mpq.2006.0033

Sparks, A., \& Reese, E. (2013). From reminiscing to reading: Home contributions to children's developing language and literacy in low-income families. First Language, 33, 89-109. doi: $10.1177 / 0142723711433583$

Suggate, S. P., Lenhard, W., Neudecker, E., \& Schneider, W. (2013). Incidental vocabulary acquisition from stories: Second and fourth graders learn more from listening than reading. First Language, 33, 551-571. doi:10.1177/0142723713503144

Suggate, S. P., Reese, E., Lenhard, W., \& Schneider, W. (2014). The relative contributions of vocabulary, decoding, and phonemic awareness to word reading in English versus German. Reading and Writing: An Interdisciplinary Journal. Advance online publication. doi:10.1007/ s11145-014-9498-z

Tramontana, M. G., Hooper, S. R., \& Selzer, S. C. (1988). Research on the preschool prediction of later academic achievement: A review. Developmental Review, 8, 89-146.

Vacc, N. A., Vacc, N. N., \& Fogleman, M. S. (1987). Preschool screening: Using the DIAL as a predictor of first-grade performance. Journal of School Psychology, 25, 45-51. doi:10.1016/0022-4405(87)90059-8

Viholainen, H., Ahonen, T., Lyytinen, P., Cantell, M., Tolvanen, A., \& Lyytinen, H. (2006). Early motor development and later language and reading skills in children at risk of familial dyslexia. Developmental Medicine \& Child Neurology, 48, 367-373. doi:10.1017/ s001216220600079x

Viholainen, H., Aro, M., Ahonen, T., Crawford, S., Cantell, M., \& Kooistra, L. (2011). Are balance problems connected to reading speed or the familial risk of dyslexia? Developmental Medicine \& Child Neurology, 53, 350-353. doi:10.1111/j.1469-8749.2010.03856.x

Wassenberg, R., Feron, F. J. M., Kessels, A. G. H., Hendriksen, J. G. M., Kalff, A. C., Kroes, M., . . Vles, J. S. H. (2005). Relation between cognitive and motor performance in 5- to 6-year-old children: Results from a large-scale cross-sectional study. Child Development, 76, 1092-1103. doi:10.1111/j.1467-8624.2005.00899.x

Wexler, M. (1998). Motor processes in mental rotation. Cognition, 68, 77-94.

White, S., Milne, E., Rosen, S., Hansen, P., Swettenham, J., Frith, U., \& Ramus, F. (2006). The role of sensorimotor impairments in dyslexia: A multiple case study of dyslexic children. Developmental Science, 9, 237-269.

Wohlschläger, A. W. A. (1988). Mental and manual rotation. Journal of Experimental Psychology: Human Perception and Performance, 24, 397-412. 
Zwaan, R. A., \& Taylor, L. J. (2006). Seeing, acting, understanding: Motor resonance in language comprehension. Journal of Experimental Psychology: General, 135, 1-11. doi:10.1037/00963445.135.1.1

Appendix I. Body-object interaction (BOI) words and ratings.

\begin{tabular}{|c|c|c|c|c|c|c|c|}
\hline Item & $\begin{array}{l}\text { Word (English } \\
\text { translation) }\end{array}$ & $\begin{array}{l}\mathrm{BOI} \\
\text { rating }\end{array}$ & $\begin{array}{l}\text { FMS- } \\
\text { manipulable }\end{array}$ & Item & Word & $\begin{array}{l}\mathrm{BOI} \\
\text { rating }\end{array}$ & $\begin{array}{l}\text { FMS- } \\
\text { manipulable }\end{array}$ \\
\hline I & Bauernhof (farm) & 1.67 & 1.33 & 19 & Kalender (calendar) & 3.00 & 4.33 \\
\hline 2 & Pinguin (penguin) & 3.00 & 2.66 & 20 & Schnalle (buckle) & 3.67 & 5.00 \\
\hline 3 & Geschenk (gift) & 4.67 & 5.00 & 21 & sägen (sawing) & 4.33 & 3.00 \\
\hline 4 & Feder (feather) & 5.00 & 5.00 & 22 & Pandabär (panda) & 2.33 & 2.33 \\
\hline 5 & Spinnwebe (cobweb) & 4.00 & 3.66 & 23 & Weste (vest) & 3.67 & 3.33 \\
\hline 6 & Ellenbogen (elbow) & 4.00 & 2.66 & 24 & Pfeil (arrow) & 2.00 & 2.67 \\
\hline 7 & jonglieren (juggling) & 3.67 & 3.00 & 25 & pflücken (picking) & 4.00 & 4.00 \\
\hline 8 & Brunnen (fountain) & 2.33 & 2.00 & 26 & Ziel (target) & 2.00 & 2.33 \\
\hline 9 & Netz (net) & 3.67 & 4.00 & 27 & tropfen (dripping) & 2.33 & 2.67 \\
\hline 10 & Schulter (shoulder) & 3.00 & 2.00 & 28 & Ritter (knight) & 3.00 & 2.33 \\
\hline 11 & anziehen (dressing) & 3.00 & 3.00 & 29 & liefern (delivering) & 3.00 & 2.67 \\
\hline 12 & Dach (roof) & 1.67 & 1.33 & 30 & Kaktus (cactus) & 2.67 & 2.67 \\
\hline 13 & spähen (peeking) & 1.33 & 1.33 & 31 & Zahnarzt (dentist) & 2.00 & 2.00 \\
\hline 14 & Lineal (ruler) & 4.33 & 5.00 & 32 & treiben (floating) & 3.67 & 2.00 \\
\hline 15 & Tunnel (tunnel) & 1.67 & 1.00 & 33 & Kralle (claw) & 2.33 & 2.67 \\
\hline 16 & Ast (branch) & 3.33 & 3.33 & 34 & Uniform (uniform) & 3.33 & 3.00 \\
\hline 17 & Umschlag (envelope) & 2.67 & 5.00 & 35 & gigantisch (gigantic) & 1.67 & 1.33 \\
\hline 18 & Raute (diamond) & 1.33 & 1.66 & 36 & pelzig (furry) & 3.00 & 3.33 \\
\hline
\end{tabular}

Note: The BOI and FMS-manipulable ratings were responses on a five-point Likert scale $(\mathrm{I}=$ not at all to 5 = very much so) to the questions: 'To what extent can a human body physically interact with the word's referent?' and 'Is the word's referent physically manipulable with your hands?', respectively. 